\title{
EFFECT OF INTERACTIVE VIDEO LENGTH WITHIN E-LEARNING ENVIRONMENTS ON COGNITIVE LOAD, COGNITIVE ACHIEVEMENT AND RETENTION OF LEARNING
}

\author{
Dr. Mohammed Kamal AFIFY \\ ORCID: 0000-0001-9248-9074 \\ College of Education \\ Imam Abdulrahman Bin Faisal University \\ Dammam, SAUDI ARABIA
}

Received: 13/10/2019 Accepted: 25/11/2019

\begin{abstract}
The importance of using the interactive video has been widely recognized in e-learning courses. However, there are several variables that can affect learners' engagement and their learning through watching digital interactive videos. the main purpose of this study is to examine whether long interactive videos can improve students' performance in tests, retention of learning in the long term, and reduce the cognitive load compared to medium and short videos. An experimental research was conducted on a sample of (63) students of the Faculty of Education at Imam Abdul Rahman University bin Faisal who are registered to study both the courses of Education Technology (EDUM 195N), and Design and Production of Multimedia (EDUM $330 \mathrm{~N})$. A three-group experimental design was used. The results were analyzed and interpreted in the light of cognitive load theory and Cognitive Theory of Multimedia Learning. In light of the research findings, the researcher presented a set of recommendations for use in the design and development of content of interactive digital video-based learning environments. The research results can mainly benefit stakeholders and education practitioners, specifically universities, schools, and companies in providing interactive digital video-based learning and training in e-learning and distance learning environments.
\end{abstract}

Keywords: Distance education, interactive digital video, video-based learning, video length, retention of learning, cognitive load.

\section{INTRODUCTION}

Recently, the use of e-learning environments both blended and full online in universities is increasingly becoming popular, where the digital video forms the cornerstone for many of e-courses content. Indeed, the increasing daily use of mobile phones cameras and digital photography cameras has led to the adoption of recording and sharing short videos by both the teachers and students, as well as the creation of a new informative culture of developing and understanding content. Thus, digital video-based learning became an essential part for teaching in different contexts and environments.

The Digital Video (DV) is considered one of the modern technologies. Video-based learning in this context is defined as the learning process through which a specific knowledge is acquired, as well as developing competencies and skills through the systematic assistance provided by the resources of the video (Giannakos, Jaccheri, \& Krogstie, 2016). The digital video is characterized by various advantages including the availability and accessibility, display control, editability as well as comments and footnotes insertion, shareability, and simplification of abstract ideas or phenomena which are difficult to conceptualize without learning media, besides the ability of communicating with the viewers at the emotional level and the cognitive level as one of strength points of the digital video. Thereby, thanks to its ability to reach the viewers' emotions, the video can have a strong positive effect on motivating learners towards the effective learning (Razis, Radzuan, \& Manan, 2018; Dash, Kamath, Rao, et. al, 2016).

There are two types of the digital video namely the linear video and the interactive video. For achieving the maximum benefit of using the learning environment based on the digital video, teachers and designer trainees 
should take three elements into consideration while designing and presenting the interactive video. These elements are reducing the cognitive load, increasing students' engagement, and achieving active learning. And these three elements together in fact form a solid ground to produce and use the interactive video as an effective tool in teaching and learning.

Watching digital lectures or digital video clips is considered an auto-organized process, where various variables may affect students' engagement and their learning through watching the interactive video. These influential variables include the showing of videos, types of videos, sources of videos, and video facilitation (Alpert, \& Hodkinson, 2019). Besides, the passing information and controlling the learner via the interactive video may increase the cognitive load and thus increases confusion of learners while learning through watching videos. The length of videos may affect the behavior of learners, specifically their engagement level and watching strategies they are using while watching the content of both long and short videos. Generally, using the interactive video during learning, and students' preference in different video types and its length form an increasingly important topic because the results available of research and studies conducted about this variable are few, while there is a persistent need to know and understand the effect of the interactive video length on improving learning performance and the retention of learning. For this reason, the primary purpose of this study is investigating whether the length of the interactive video affects the cognitive achievement and its retention, besides the cognitive load for university students.

\section{THEORETICAL FREAMWORK}

\section{Interactive Digital Video (IDV)}

There are two types of digital videos, linear and interactive video. The linear video is watched by the viewers since the beginning till the end in a linear process without stop or interaction of viewers with its content. And this type is closely similar to watching television which is known as visual consumption from television that results in a superficial learning with a short retention term of the acquired learning effects. In this linear type, the absence of the learner's ability to interact with the video is one of its main drawbacks. In that the inability to interact leads to weak cognitive engagement of the viewer which forms a big challenge for learning. When learners do not have control over their learning, their time allotted to learning and their focus decrease, which constitutes a threat for learning (Palaigeorgiou, \& Papadopoulou, 2018).

The interactive video is a type which includes interactive aspects such as click to explore, answering questions, clicking hot spots, or answering surveys and voting, besides other various interactive options which urge students to interact with the activity being presented and its content; and this insures that the style of the video in transmitting information is not linear. Thus, the interactive video is the opposite of the narrative linear style of the traditional videos (Petan, et. al., 2014). Shelton at al., (2016) have defined the interactive video that it is the video which includes aids which urge students to interact with the activity and its content, with an appropriate design that meets students' needs (Shelton, et. al., 2016). In the same respect, Meixner (2017) defined the interactive video as a video which relies on hypermedia which in turn combine both the features of non-linear video and a dynamic display of information in the video or in parallel with them (Meixner, 2017).

The interactive video works on segmenting complex ideas into small segments that can be understood which provides the learner with the ability to process it in a fast manner. Besides, it reduces the reading load imposed on learners through presenting content in a visual and engaging way. Basically, interactive videos transform the learning process from a one-way style into a process of exchanging information through enabling the learner to play an active role. Indeed, any linear video can be altered into an interactive video with limitless procedures to generate deeper engagement (Shahrokni, 2018; Green,2016).

The previous studies (Pandey, 2018; Sauli, Cattaneo, \& Van der Meij, 2018; Wachtler, Scherz, \& Ebner, 2018; Wachtler, Hubmann, Zohrer, et. al, 2016; Petan, et. al., 2014) have revealed a considerable number of the characteristics distinguishing the interactive video as follows:

1. Divisibility into segments and re-usability: The interactive video can be divided into small segments for learning, which means that there is a need to create small connected segments of information, and short videos which present explanations instead of making one whole video to process all the content 
and information. In addition, the structure of divisible information allows continuous adaptation easily, and guarantees reusing it according to the learning objective (Petan, et al., 2014).

2. Interactivity: Interactivity enables the viewers to control content and communicate with different parts of the video at all levels. Furthermore, it helps learners build their own knowledge productively. And the active learners can integrate new information in their memory more than passive learners.

3. Dynamic presentation: Dynamic presentation is characterized by being multisensory because it triggers or targets different senses, where movement is used to attract and obtain attention (Baldwin, \& Ching, 2017).

4. Understanding evaluation tool: Tools of understanding evaluation of interactive videos allow not only allocating videos for students to watch, but its grace stretches also to enabling students with understanding and assimilating content in the appropriate time through asking question(s) by the teacher to be answered by students before proceeding to the rests of the video. This feature is considered ideal for teachers who want to ensure that their students have really watched the assigned videos, and that they deeply assimilated concepts and information presented through the video content (Staff, 2014).

5. Monitoring and follow-up (Analytics): One of the main and most important features available in platforms of producing and managing interactive videos is analytics. This feature enables teacher to easily know students who watched the video to the end (the assignment), or to ensure that they have assimilated the concept presented. In addition, analytics feature offers important and decisive information about students' success on different levels including misunderstanding points, the level of effort made, persistence, and the time spent by students to accomplish the mission (Blackstock, Edel-Malizia, Bittner, et. al, 2017).

6. Non-linear navigation ability: This feature allows clicking signs that provide complementary and additional information. Besides, it allows learners to proceed and go in different paths within the video (based on learners' choice and the main points of decision) through implementing discharge option technology.

7. Consistency with standards of web-based teaching technologies: This feature is also known as Shareable Content Object Reference Model (SCORM). And this model contributes to presenting interactive videos on all platforms of e-learning systems' management, besides allowing for tracking and following-up learners' progress.

However, among challenges that emerge while using the interactive videos as the main content is how to make learning more interactive and less negative? Researchers who have studied learning through interactive videos have defined interaction in relatively different ways. Still, with regard to most of the previous studies (Shelton, et. al., 2016; Wachtler, et. al, 2016; Delen, et. al., 2014; Merkt \& Schwan 2014), it can be stated that the interactive video includes many forms for designing interaction as shown below:

- Video re-watchability or jump forward through its content or its parts or pausing to process content.

- Adding pointers or text phrases, where light is shed on important information either by inserting pointers, signs, or textual naming to direct learners to specific aspects in the video, or through adding comments and explanations in the video by the teacher.

- Embedded questions which are organized into two types: rhetoric questions which mean anticipating what will happen next by students, where students answer the questions before watching the rest of the video which will reveal the related scientific facts; the inductive questions which are used to help students interpret hypotheses, build explanations, and enhance their knowledge.

- internal video links allowing students to navigate within the video in a faster manner through clicking randomly on video progress bar.

- External video links are also supported. They are links to different learning websites which are presented through textual naming on the video. These external links mostly aim to enable students with further exploration of more related topics from other sources apart from those contained in the learning path. 
- reflexive pauses, where the video is paused urging students to think expandingly about the learning subject and discuss it with classmates. And with this urging on thinking, students acquire skills of self-organization, and think about how to accomplish a given mission.

- answer pop-up e-questions to direct focus, or to ensure understanding. The interactions in the questions come in the following forms: Button click, fill in the blanks, Single choice assessments, Multiple choice assessments, Drag and drop, and Hotspots.

There are various platforms of producing interactive videos such as Edpuzzl (https://edpuzzle.com), HapYak (http://www.hapvak.com), Zaption (https://www.zaption.com), and PlayPosit (https://www.PlayPosit. com). These platforms are available for teachers to use them through the internet in the integrated learning e-courses (Blackstock, et. al., 2017; Staff, 2014). These e-platforms are used to produce and manage the interactive video. And they enable users to search and navigate various video services available directly on famous video show platforms such as YouTube, TED, Vimeo, TeacherTube, and others, besides enabling users to upload their own videos. In addition, there is a tool available for customized drawing through which a specific content can be highlighted in the video with circles or colors. They also allow for dividing learning videos through adding parts or chapters, subsections, or pop-up textual comments, as well as adding interactive questions of different styles, forms, hotspots, or control buttons by teachers.

In the light of these advantages, interactive digital video is considered fundamental in e-learning. This is because it assists learners to understand concepts and complex procedures which cannot be understood through texts or drawings only. Besides, it provides a sensory learning environment which supports the understanding of the learners to recall information in a better way (Fern, Givan, \& Siskind, 2011). It is used in many cases in e-learning including clarifying concepts, explaining texts, delivering content and assisting understanding, presenting events, attitudes, and processes. Furthermore, it is used as a tool in training on scientific skills, projects and collaborative learning, on-time formative assessment, in addition to giving feedback to learners. Thus, video-based learning is considered one of the most distinguished and effective learning media which can be integrated with modern teaching strategies including micro teaching, flipped classrooms, or gamification-based learning, and teaching strategies through mobile devices, besides its compliance with the nowadays trends of digital learning. Thus, it works on providing learners with a sensory learning environment that supports them to understand more information and better recall (Palaigeorgiou, Papadopoulou, Kazanidis, 2018; Song, Pusic, Nick, et. al., 2014).

Numerous researchers have studied the effect of using the interactive video on both teaching and learning processes. The findings of the study conducted by (Jill, Wang, \& Mattia, 2019) revealed that there was an improvement in students' performance in tests, their engagement, motivation, and their perception. Besides, the results also revealed that videos are considered scaffolds for learning as they provide the appropriate support to students when needed throughout a timeline including study behavior before the lecture, during the lecture, and after the lecture (Rismark, \& Sølvberg, 2019). Another study conducted by (Ariffin, \& Ismail, 2019) revealed the effectiveness of icon-based and narration-based interactive video as a learning tool for teaching English vocabulary to high school students of the first level in Malesia. The results of the study carried out by (Hung, \& Chen, 2018) have also showed that the performance of the students who practiced learning through the interactive video was better at the level of understanding and retention of information more than the others who did not use videos. The video can be used as an appealing teaching source, or in self-directed teaching, or for complementing face-to-face teaching to provide the opportunity of doing exercises and discussions in the classroom (Betrancourt, \& Benetos, 2018).

In the same respect of the interactive video merits, the findings of the previous studies revealed that the interactive video does not exhaust students with any extra cognitive load. In another study (Palaigeorgiou, \& Papadopoulou, 2018), the findings revealed the fact that the learning environment through the interactive video and tablets together helped students achieve a high level of self-control, self-discipline, self-learning, besides enabling them very successfully to manage the progress of their learning. The study of (Razis, et. al., 2018) has also showed that the learners who have used the interactive video to accomplish missions showed a big improvement in retention of information in their memory; and the grades they achieved in general were higher compared to the other group who did not use the video, while the study stressed that the use of the interactive video, as an interactive tool, played a major role in increasing retention of information in the memory, besides supporting learning. 


\section{Video Length and Cognitive Load}

Cognitive load is considered one of the main priorities to take into consideration during design and production process of teaching materials, including the digital video. Cognitive load is defined as the amount of information which are stored and processed in the working memory (Sweller, 1994). Cognitive load theory is based on the assumption that the working memory has a limited stocking capacity, and thus a limited processing capacity. Among the fundamentals of the cognitive theory is that specifications of the working memory structure should be taken into consideration while designing teaching materials (Plass, Moreno, \& Brunken, 2010; Sweller, Ayres, \& Kalyuga, 2011).

Cognitive load theory has specified three different types of the cognitive load for every learning process. These types are intrinsic cognitive load, germane cognitive load, and extraneous cognitive load (Wang, \& Antonenko, 2017; Brame, 2016; Paas, Tuovinen, Tabbers, \& Van Gerven, 2003). The intrinsic cognitive load is the load imposed by the study subject, and it is relatively leveled by the levels of inter-relations within the study subject. Germane load refers to the required cognitive activity made by the learner to achieve the desired learning outcomes such as the ability to compare, analysis, and interpretation. The main objective of these activities is to enable the learner to understand content in connected ideas. The third type, the extraneous cognitive load means the cognitive effort made by the learner but without achieving the desired learning outcomes. The cause behind this is mostly mal-design or mal-preparation of lessons by teachers. Among the things that cause the extraneous load are giving unclear instructions, or extra and unimportant information which form a burden on learners. As well, this can also be caused by undesired prejudices or stereotypes. Through the definition of cognitive load types, it becomes clear that both of intrinsic load and the extraneous load form an obstacle that hinders learning, while germane load facilitates learning (Plass, et. al., 2010).

In the light of the abovementioned information, it can be stated that designing multimedia materials in the interactive video-based learning environment should be done in a way that contributes to reducing the extraneous load; and rather, teachers should provide cognitive resources to increase processing content through the germane load. Thereby, the main objective from designing teaching materials for learning in the interactive video environment is to reduce the extraneous load to avoid extra cognitive load, and instead maximizing the level of the germane load to guarantee the achievement of the desired learning outcomes by the learners (Kruger, \& Doherty, 2016).

Videos are increasingly being used in teaching and training. However, they can lead to facing specific difficulties relating to employees' learning because of the temporary nature of information presented in the video, or because the learner cannot control the speed of the video or the length of the show. These effects can be explained with reference to the cognitive theory of learning through multimedia as presented by (Mayer, 2014, p.72). This theory is based on the thought that information are processed by two channels, auditory and visual, which implies that each channel has a limited capacity and limited processing ability. When a person watches a video, auditory and visual information are processed simultaneously by these two sensory channels. And the problem lays in the continuous flow of information being presented by the video which may result in loading heavy cognitive burden (Sweller, 2010). If information are given in a highly fast way to the learner, without enabling the latter to control the speed of the video and its length, the intrinsic load may rise because both the channels will be loaded (Mayer, Pilegard 2014).

Various studies (Mayer \& Moreno, 2003) have investigated the effects resulted from segmenting learning through the video. The findings showed that segmenting reduced the mental effort, made the learning experience easier, and improved knowledge transmission. This can be explained by the fact that segmenting reduces the cognitive load resulting from the passage of information. In the dynamic segmented show, information flow is segmented into small units; and the temporary pauses between these unites provide students with the time needed to cognitively process the presented information in the previous video segment, without the need to deal with a set of new information at the same time (Biard, Cojean, \& Jamet, 2018). In the same respect, Rudolph (2017) stated that segmenting focuses on segmenting the parts of the learning multimedia into smaller topics distributed throughout the lesson which allows students to learn one topic before moving to the next one (Rudolph, 2017). 
In addition, the cognitive load theory has effects on designing the length of the video. In that using short videos helps reduce the extraneous load and increase the germane load. Indeed, using short videos provides the ability to segment information into small learning units which comply with the limited capacity of the working memory (Slemmons, Anyanwu, Hames, et. al., 2018).

Lessons derived from the cognitive theory of multimedia learning and the cognitive load theory have direct effects on designing, making, and using interactive videos especially while processing the length of the videos that is most appropriate to students (Slemmons, Anyanwu, Hames, et. al., 2018). However, it seems that the practical implementation of these guidelines is limited. Besides, the quantitative and qualitative data which support the most effective way of creating the interactive video and its ideal length are limited too. Thus, this research aims at investigating these factors, namely investigating the effect of length of the interactive video that is most appropriate for learning and the retention of learning, as well as the cognitive load.

Few studies have been conducted about the effect of the interactive video length on some learning outcomes. Risko et al., (2012) have conducted an experiment on a sample of students who used a 60-minute length video. The focus during the experiment was laid on mental stray periods of the learners and their ability of content retention in their memory. The results showed that cases of mental stray of learners were high, and that the percentage of information retention in their memories decreased after they had watched the video (Risko et al., 2012).

Guo et al., (2014) have also studied the length of videos and the time learners spent watching edX videos in the frame of Massive Open Online Courses (MOOC). The researchers analyzed the results of students' video watching where they noticed that the average of watching time for videos which are less than 6 minutes was very close to $100 \%$. And this reflects that learners were watching the whole video. In contrast, they noticed that the longer the video is, the lower interaction of learners becomes, reaching $50 \%$ with some videos which have a length of 9 and 12 minutes, while interaction percentage with videos of 12 to 40 minutes length decreased to $20 \%$. Thus, it can be concluded that the highest percentage of learners' interaction with videos was with the ones of less than 6 minutes length, which reflects that videos of more than 6 to 9 minutes can be a mere waste of effort (Guo, et. al., 2014).

In another study (Slemmons, Anyanwu, Hames, et. al., 2018), the researchers investigated the effect of video length on learning in flipped classrooms environment during two semesters in middle school science classes to determine the ideal video length that can enable effective learning, increase retention and support students' motivation. The results indicated that although the assessment grades that followed short videos directly were a little higher, but there was no big difference between them and the assessment grades that followed one long video. On the other hand, it seemed that retention of learning content in the short term was not affected by the video length, but the percentage of retention for male students and students who suffer from learning difficulties in the long term was higher after watching short videos compared to long videos. And students stated that they were more engaged, more focused, and that they maintained more content retention after watching the short videos.

\section{STATEMENT OF THE PROBLEM AND QUESTION OF RESEARCH}

The importance of using the interactive video has been widely recognized in e-learning courses. However, there are several variables that can affect learners' engagement and their learning through watching digital interactive videos including the length of the video. In this regard, there are inconsistent results of previous studies which studied the effect of the video length on improving the learning outcomes of students and the cognitive load. Results of various previous studies revealed that there is some inconsistency about the length of the video appropriate for the interactive video. While some of the previous studies (Risko et al., 2012; Guo, et. al., 2014) revealed the preference of short videos over long ones relating to learning and retention of content, other studies (Slemmons, Anyanwu, Hames, et. al., 2018) saw that retention of learning content in the short term is not affected by the length of the video, and that there is no preference between short videos and medium videos relating to their effect neither on the cognitive load of learners, nor on increasing learners engagement or achieving the active learning. On the other hand, the quantitative data that determine the appropriate length of videos for enhancing genuine learning and student's engagement are limited (Slemmons, Anyanwu, Hames, et. al., 2018). 
Based on that, the main research question of this study is whether long interactive videos can improve students' performance in tests, retention of learning in the long term, and reduce the cognitive load compared to medium and short videos? The following sub-questions can be derived from the main question as follows:

Q1: What is the effect of difference in the interactive video length (Short $<6$ minutes, Medium 6-12 minutes, and Long $>12$ minutes) on cognitive achievement in principles and skills of digital photography?

Q2: What is the effect of difference in the interactive video length (Short $<6$ minutes, Medium 6-12 minutes, and Long $>12$ minutes) on retention of learning?

Q3: What is the effect of difference in the interactive video length (Short $<6$ minutes, Medium 6-12 minutes, and Long $>12$ minutes) on learners' cognitive load?

\section{RESEARCH HYPOTHESIS}

1. There are statistically significant variances in students' performance in the three experimental groups on the immediate cognitive achievement test due to the difference in the digital interactive video length (short $<6 \mathrm{M}$, medium $6-12 \mathrm{M}$, long $>12 \mathrm{M}$ ).

2. There are statistically significant variances in students' performance in the three experimental groups on the cognitive achievement post-test (retention) due to the difference in the digital interactive video length (short $<6 \mathrm{M}$, medium 6-12M, long $>12 \mathrm{M}$ ).

3. There are statistically significant variances in students' performance in the three experimental groups on the cognitive load scale due to the difference in the digital interactive video length (short $<6 \mathrm{M}$, medium 6-12M, long $>12 \mathrm{M}$ ).

\section{METHODOLOGY}

\section{Methodology of the Research and Its Variables}

The research includes one independent variable which is the length of the interactive video with three experimental treatments namely short videos less than 6 minutes, medium 6-12 minutes, and long more than 12 minutes. Besides, it includes two dependent variables which are: a) cognitive achievement and learning retention, b) learner's cognitive load. The researcher used the experimental method and the experimental design with three groups, and a post-measurement to measure the effect of the independent variable on the dependent ones as shown below in Figure (1).

\section{Research Sample}

The sample of the study was selected deliberately. The number of the selected sample as the research community is 63 students from Education Faculty who are registered to study both the courses of Education Technology (EDUM 195), and the Design and Production of Multimedia (EDUM 330N). The sample was divided based on the experimental design of the research into three groups. Group one contained 22 students, group two 20 students, and group three 21 students. 


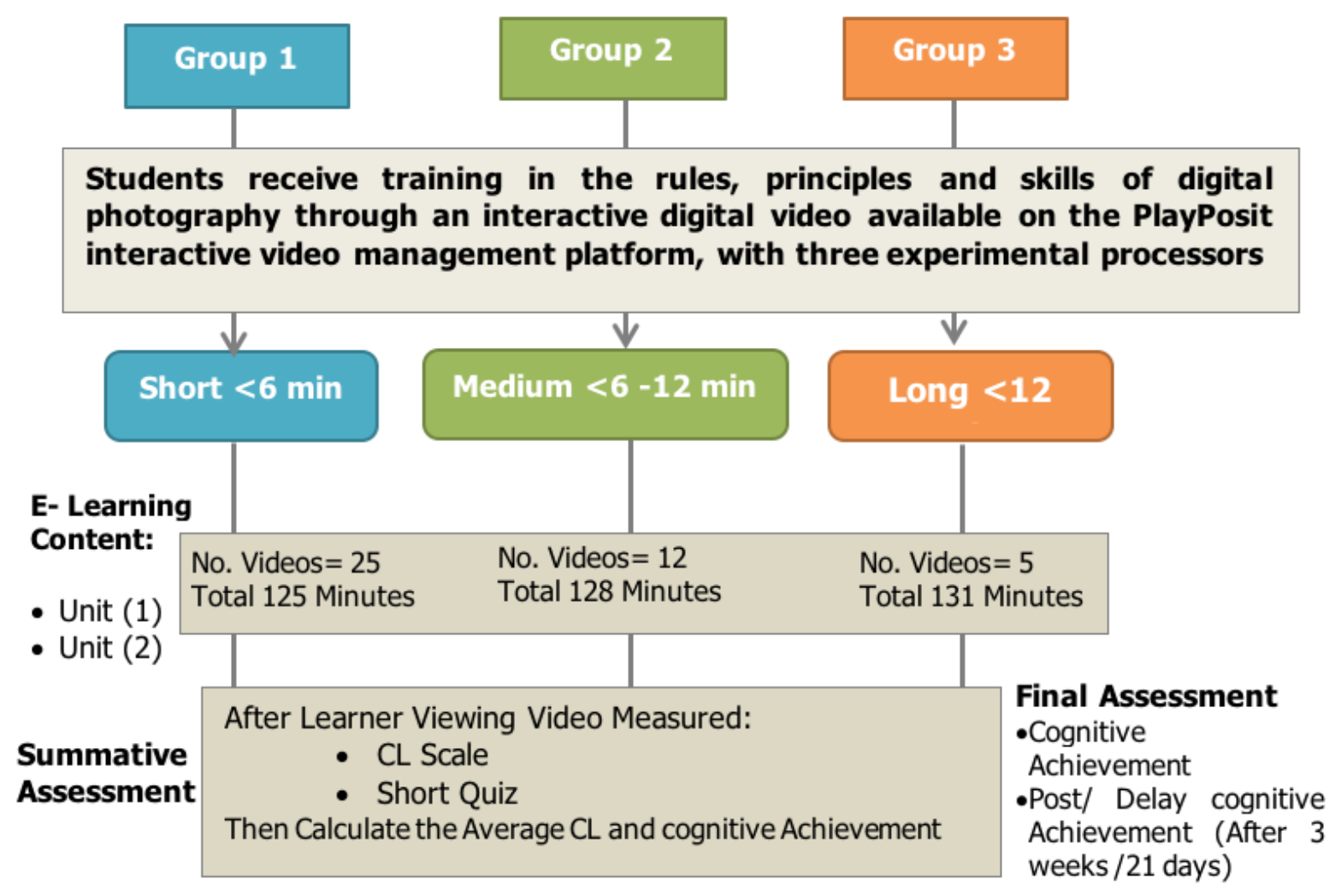

Figure 1. Experimental design for research

\section{Design and Development of the Research Experimental Treatment}

The experimental treatment of the research was conducted through preparing an instructional design for digital interactive video-based environment with three treatments and measuring its effect in: a) cognitive achievement and retention of learning, b) the cognitive load of students of Education Faculty.

We designed the experimental treatment and developed it by using (ADDIE) model. The ADDIE model is a systematic instructional design model consisting of five phases: Analysis, Design, Development, Implementation, and Evaluation (Branch, 2009).

\section{Analysis Phase}

The following steps were taken.

- Determining the characteristics of learners and their learning needs: The learners are from the Faculty of Education who are registered to study the course of Education Technology (EDUM 195N), and the Design and Production of Multimedia (EDUM 330N). These courses require that students acquire the prerequisite skills to produce necessary digital photographs for teaching activities using photography cameras and smart phone cameras. The acquisition of digital photography skills is considered one of the important desired outcomes for students of Education Faculty considering them 'teachers' and 'designers' of different learning resources. However, the researcher while teaching these courses noticed students' weakness in the performance and practical skills required in digital photography course. This detected weakness can mainly be attributed to shortage of time in faceto-face learning and shortage of practicums which should accompany theoretical lectures. Thereby, there rises a need for training students on practical skills using the interactive video technology and designing a learning environment for this purpose. 
- Specifying the general objective: The experimental treatment aimed that students of Education Faculty acquire the principles of digital photography, its rules, techniques, and skills. The behavioral objectives were formulated.

- Specifying the learning content: In light of the learning outcomes mentioned above, the learning content was specified for the experimental treatment material in the two units of Rules of Digital Photography, and its Principles and Skills.

- Specifying the prerequisite priorities for digital video-based environment of learning: The platform of Interactive Video Management PlayPosit was used to design and produce interactive videos, and to manage the learning environment. Each teacher and each student in the experimental groups can access the platform and practice learning activities and their missions according to their experimental group.

\section{Design Phase}

At this stage, digital video lessons have been designed and categorized into three experimental treatments. All the experimental treatments are conducted with students who are taking training in digital photography skills through the interactive video-based learning environment which is available on the Interactive Video Management platform PlayPosit. The video length in the first experimental treatment is short $<6$ minute, the second experimental treatment is medium 6-12 minute, and the third experimental treatment is long $>12$ minute. The three experimental treatments have been designed based on the following conditions:

- Allocating an interactive video for each skill or rule of photography, where the video focuses training on practical skills of digital photography. The videos chosen were the ones which are new, high view rates, and free of advertisements.

- Design of interaction in the interactive video contained the following: re-watch the video or jump forward throughout its contents and parts, add comments and explanations on videos, and answer pop-up e-questions to direct focus or to check understanding. The interactive questions were in forms of Fill in the blanks, Single choice assessments, Multiple choice assessments.

- Reducing cognitive load of learners was taken into consideration while designing the interactive videos through using signs to shed light on important ideas, information, and concepts. Besides, key words are used on the screen to focus on the most important elements; and pruning technique was used to remove obstructive information like removing music or complex backgrounds, besides making the video as part of the homework to increase learners' motivation.

- Designing learning activities, its missions, and timeline plans of implementation: Learning activities included two activities.

- Activity 1 was about taking digital photographs -for educational purposes- at the end of each lesson of the practical lessons aimed for training students on the required skill. Then, students upload it on the learning management system for discussion and see the extent to which the student adhered to the rules of digital photography and its skills in the product.

- Activity 2 was specified for preparing a teaching presentation of one of the teaching lessons by students in their specialty using photographs they had taken with their own cameras, besides presenting a scenario specifying the desired learning objectives to achieve with the photo parts appropriate for these objectives and specifying their specifications. And these activities should be carried out in accordance with the rules of digital photography and its skills. Also, students were provided with a list of the product evaluation standards (skills of the students in taking digital photographs) to guide them while accomplishing the assigned activities. 


\section{Development Phase}

- The actual production of learning content through the digital interactive video in light of standards of learning video design mentioned herein in this research is done using PlayPosit platform, which is one of the platforms specified for this purpose. As a result, 42 videos which cover all the elements of teaching content for training on the required skills were grouped in consistency with achieving the purpose from the materials of the three experimental treatments. The videos were distributed on three groups. 25 short videos were specified for the first experimental treatment where the length of each video is less than 6 minutes, with a time total of 125 minutes for all the 25 videos to explain the required learning skills. The second experimental treatment contained 12 medium videos of 6-9 minutes for each with a time total of 128 for all the 12 videos to explain the required learning skills. Finally, 5 long videos of more than 25 minutes for each with a total of 131 minutes were specified for the third experimental treatment to explain the required learning skills.

- Structural evaluation of digital interactive videos: The initial draft was presented to experts and the specialized to ensure its appropriateness for achieving the objectives, the required skills aimed for students, the quality of its technical production, and its consistency. The arbitrators' opinions were analyzed, and necessary modifications were made in light of the structural evaluation. Then, the final version was prepared and made ready for publication on the platform of interactive video management.

\section{Implementation Phase}

At this stage, tools and experimental treatments were carried out, where students took the practical training on the practical skills of digital photography through the three experimental treatments of the interactive video-based learning in this research. The students accomplished the practical assignments and the required missions manifesting in designing teaching projects using digital photographs. The implementation of the experiment lasted for 5 study weeks starting from the fifth week until the tenth week of the second semester of the university year 2108/2019, according to the timeline specified for the program courses.

\section{Evaluation Phase}

At this stage, the final evaluation of the post-application of measurement tools has been carried out to know the effect of the video showing length (short $<6$ minutes, medium 6-12 minutes, and long more than 12 minutes) on: the cognitive achievement, learners' cognitive load, and then re-application of the postapplication of the achievement test after 21 days from the first application to investigate the retention level of learning by students.

\section{Measurement Tools}

\section{Cognitive Achievement Test}

The researcher prepared the cognitive achievement test to measure knowledge and concepts related to "Basics of Digital Photography, its Techniques and Skills'. The test was formulated in the style of multiple choices, and true or false questions. Instructions of the test were formulated in an easy and clear style to enable students' understanding. The instructions included the test objective, test time, the number of the test items, and how to answer vocabulary questions. The test included 50 questions to be corrected electronically. Each correct answer from true-or-false and multiple-choice questions is graded one point, while incorrect answers are graded 0 point. The total full-mark score of the test mark is 50 points. Face validity of the test was estimated by a group of arbitrators specialized in education technology to ensure the scientific and linguistic appropriateness of its vocabulary for the objectives aimed, and to ensure that it is ambiguity free. Besides, instructions of the test have been reviewed to ensure easy understanding and their formulations. Remarks provided by the arbitrators were taken into consideration during the preparation of the last version of the test. The test was applied on 13 students as an exploratory sample apart from the main research sample to ascertain that its questions and instructions are clear, as well as calculating its stability. The test stability 
which was calculated using Cronbach's alpha coefficient recorded (0.94), which is a high value indicating that the test has a high degree of stability qualifying it to be a suitable research tool for the purpose of this research (Appendix 2).

\section{Cognitive Load Scale}

The scale's objective was measuring the cognitive load of learners after watching the learning interactive videos. For building the scale, various previous studies which studied measuring the cognitive load have been explored (Josephsen, 2018; Kruger, \& Doherty, 2016; Leppink, et. al., 2013, 2014; Paas. et. al. 2003a). The researcher developed the scale prepared by (Leppink, et. al., 2013, 2014) because this scale measures all the three types of the cognitive load namely the intrinsic, extraneous, and the germane cognitive load based on learners' self-evaluation elements after having just finished practicing a certain mental activity. The scale contained 14 vocabulary items which measure the cognitive load, distributed as: 4 vocabulary items $(1-4)$ measure the intrinsic cognitive load, 4 vocabulary items (5-8) measure the extraneous cognitive load, 5 vocabulary items (9-13) measure the germane cognitive load, and the 14th vocabulary item to measure the overall cognitive load. To calculate the way of scoring the scale's grades, all items of the scale are presented to examinee learners after having just finished practicing a mental effort activity (lecture or discussion session, training on skills, learning via multimedia, or learning via watching videos). The examinee learners answer each item of the scale's items on a graded measurement (0-10), where 0 means that the item does not absolutely apply to the examinee learner, and 10 means that the item totally apply to the examinee learner.

The face validity of the scale was applied by presenting it to a group of arbitrators to obtain their opinion about the scale. The arbitrators pointed out some required modifications in terms of linguistic formulation of some expressions. The pointed expressions were modified as required by the arbitrators. Besides, the internal consistency was calculated through calculating correlation coefficients between the grades of the exploratory sample (13 students) for every item of the scale, and their grades on the scale as a whole. The values of correlation coefficient ranged from 0.58 to 0.91 which is a function value at 0.05 . In addition, correlation coefficient between every dimension of the scale and the scale in the overall was calculated. The values of correlation coefficient for the three dimensions of the scale are $(0.76,0.78,0.82)$ for the intrinsic, extraneous, and the germane dimension respectively. The scale answer time was also calculated. And it showed that the answer time does not exceed 15 minutes with 5 minutes to read instructions thus making a scale answer time of 20 minutes. After calculating the validity and stability of the scale, it became ready in its final version consisting of 14 items. Thus, the overall grade of the scale is 140 points, which is the highest mark, while the lowest mark is 14 grades, and the neutral mark is 70 . The overall cognitive load is considered high when exceeding 70, and neutral when the examinee's grade is less than 70 grades (Appendix 3).

\section{Statistical Analysis}

The statistical treatment of data was conducted using SPSS program version 20. The researcher used the suitable statistical methods to achieve the study results as follows: Pearson's correlation coefficient to measure the internal consistency of the measurement tools, Cronbach's alpha coefficient to measure the stability of the scale, arithmetic averages, and standard deviations as a descriptive statistics of data which reflects students' performance on measurement tools, and One-way Variance Analysis (ANOVA) test to calculate the effect of the interactive video length (Short $<6$ minutes, medium 6-12 minutes, and long more than 12 minutes) on the research variables, and to calculate variance significance between averages of the three experimental groups, besides comparing the averages using Scheffe test. 


\section{FINDINGS}

\section{Answering the First Question}

What is the effect of difference in the interactive video length (Short< 6 minutes, Medium 6-12 minutes, and Long > 12 minutes) on cognitive achievement in principles and skills of digital photography?

One-way Analysis of Variance (ANOVA) was calculated to know the effect of difference in the interactive video length (short < 6minutes, medium 6-12 minutes, and long > 12 minutes) on cognitive achievement, and the findings are as illustrated in Table (1) and Table (2).

Table 1. Arithmetical averages and standard deviations for IDV length (Short <6M, Medium 6-12 M, Long $>12 \mathrm{M}$ ) on the performance of the cognitive achievement test

\begin{tabular}{cccccccc}
\hline \multirow{2}{*}{$\begin{array}{c}\text { IDV length } \\
\text { Test }\end{array}$} & \multicolumn{2}{c}{ Short $<6 \mathrm{M}$} & \multicolumn{2}{c}{ Medium $(6-12 \mathrm{M})$} & \multicolumn{2}{c}{ Long $>12 \mathrm{M}$} \\
\cline { 2 - 8 } & Mean & SD & Mean & SD & Mean & SD \\
\hline Cognitive Achievement $=50$ & 47.23 & 2.16 & 35.55 & 3.15 & 37.43 & 2.39 \\
\hline
\end{tabular}

Table 2. ANOVA, Analysis of the one-way variation of the IDV length (Short <6M, Medium 6-12 M, Long $>12 \mathrm{M}$ ) on the performance of the cognitive achievement test

\begin{tabular}{ccccccc}
\hline Test & Variable source & $\begin{array}{c}\text { Sum of } \\
\text { squares }\end{array}$ & df & $\begin{array}{c}\text { Means } \\
\text { Squares }\end{array}$ & "F" value & $\begin{array}{c}\text { Significance } \\
\text { Indicator }\end{array}$ \\
\hline \multirow{2}{*}{$\begin{array}{c}\text { Cognitive } \\
\text { achievement }=50\end{array}$} & Between Groups & 1679.98 & 2 & $\mathbf{8 3 9 . 9 9}$ & \multirow{2}{*}{0.000} \\
& Within Groups & 401.96 & 60 & $\mathbf{6 . 6 9}$ & \multirow{2}{*}{0.38} & 0.000 \\
& Total & 2081.93 & 62 & & & \\
\hline
\end{tabular}

The results in table (2) indicate that there are statistically significant variances at the fuction value 0.01 between averages of students' grades in cognitive achievemnt test where $\mathrm{F}$ value is significant. And this means that the difference in the interactive video length (short $<6 \mathrm{M}$, medium $6-12 \mathrm{M}$, and long $>12 \mathrm{M}$ ) has an effect in the test of cognitive achievemnt, which means that the first hypothesis validty is confirmed. To dtermine the place of these variances, Post Hoc and Scheffe methods were used to uncover variances between groups in pairs as shwon in Table (3).

Table 3. The post binary comparisons between the test score averages of the cognitive achievement for the three research groups

\begin{tabular}{cccccc}
\hline Test & Style $(\mathrm{I})$ & Style $(\mathrm{J})$ & $\begin{array}{c}\text { Mean deferent } \\
(\mathrm{I}-\mathrm{J})\end{array}$ & $\begin{array}{c}\text { Significance } \\
\text { Indicator }\end{array}$ & $\begin{array}{c}\text { Size effect } \\
(\text { Eta Square } \eta 2)\end{array}$ \\
\hline $\begin{array}{c}\text { Cognitive } \\
\begin{array}{c}\text { achievement } \\
=50\end{array}\end{array}$ & Short $<6 \mathrm{M}$ & $\begin{array}{c}\text { Medium } \\
(6-12 \mathrm{M})\end{array}$ & $11.68^{*}$ & 0.00 & 0.807 \\
Long $>12 \mathrm{M}$ & $9.79^{*}$ & 0.00 & 0.08 \\
\hline
\end{tabular}

The results presented in Table (3) reveal that the performance of students who watched the interactive video with short length, short $<6 \mathrm{M}$, achieved high results in cognitive achievemnt compared to the perfomance of students who watched the medium video length, medium6-12M, and students who watched long videos, long $>12 \mathrm{M}$. Variances with statistical significance were found at the value 0.01 between the performance of the three groups in cognitive achievement in favor of students who watched the short interactive videos, short $<6 \mathrm{M}$. On the other hand, no difference occurred between performance in the cognitive test of students who watched the medium interactive videos, medium 6-12M compared to students who watched the long interactive videos, long $>12 \mathrm{M}$, thus there are no statistically significant variances between them. 
Besides, the effect size was calculated using the equation of Eta ( $\eta 2)$. The effect size between the three experimental groups reached 0.807 in performance of cognitive test. This result indicates that there is a big effect size of the independent variable in the variance between the groups relating to its effect on cognitive achievement, and the strong effect of the experimental treatment of short video length, short $<6 \mathrm{M}$ in cognitive achievement compared to the performance of students who watched videos with medium and long length.

\section{Answering the Second Question}

What is the effect of difference in the interactive video length (Short< 6 minutes, Medium 6-12 minutes, and Long > 12 minutes) on retention of learning?

One-way Analysis of Variance (ANOVA) was calculated to know the effect of video length (short $<6 \mathrm{M}$, medium 6-12M, and long $>12 \mathrm{M}$ ) in the post-performance of cognitive test on retention of learning. The results obtained are presented in Table (4), Arithmetical averages and standard deviations for IDV length, and Table (5), Analysis of the one-way variation of the IDV length.

Table 4. Arithmetical averages and standard deviations for IDV length (Short $<6 \mathrm{M}$, Medium 6-12 M, Long $>12 \mathrm{M}$ ) inn the performance of the post/delayed cognitive achievement test

\begin{tabular}{ccccccc}
\hline \multirow{2}{*}{$\begin{array}{c}\text { IDV length } \\
\text { Test }\end{array}$} & \multicolumn{2}{c}{ Short $<6 \mathrm{M}$} & \multicolumn{2}{c}{ Medium (6-12 M) } & \multicolumn{2}{c}{ Long $>12 \mathrm{M}$} \\
\cline { 2 - 7 } & Mean & SD & Mean & SD & Mean & SD \\
\hline $\begin{array}{c}\text { delayed Cognitive achievement (after } \\
\text { 21Day/3week)=50 }\end{array}$ & 47.05 & 1.36 & 29.95 & 2.61 & 30.52 & 2.80 \\
\hline
\end{tabular}

Table 5. ANOVA, Analysis of the one-way variation of the IDV length (Short $<6 \mathrm{M}$, Medium 6-12 M, Long $>12 \mathrm{M}$ ) on the performance of the delayed cognitive achievement test

\begin{tabular}{ccccccc}
\hline Test & Variable source & $\begin{array}{c}\text { Sum of } \\
\text { squares }\end{array}$ & df & $\begin{array}{c}\text { Means } \\
\text { Squares }\end{array}$ & $\begin{array}{c}\text { "F" } \\
\text { value }\end{array}$ & $\begin{array}{c}\text { Significance } \\
\text { Indicator }\end{array}$ \\
\hline $\begin{array}{c}\text { Between } \\
\text { Groups }\end{array}$ & 4045.08 & 2 & 2022.54 & & \\
$\begin{array}{c}\text { Post/delayed Cognitive } \\
\text { achievement (after } \\
\text { 21Day/3week)=50 }\end{array}$ & $\begin{array}{c}\text { Within Groups } \\
\text { Between } \\
\text { Groups }\end{array}$ & 325.14 & 60 & 5.419 & 373.2 & 0.000 \\
\hline
\end{tabular}

The results in Table (5) indicate that there are statistically significant variances at function value 0.01 between avergaes of students' grades in the performance of the coginitive post-test, where the $\mathrm{F}$ values were significant. This means that the difference in the length of the interactive video (short $<6 \mathrm{M}$, medium $6-12 \mathrm{M}$, and long $>12 \mathrm{M}$ ) has an effect on the performance of the cognitive post-test for students in retention of learning, which means that the second hypothesis validity is confirmed. To detrmine the place of these variances, Post Hoc post-comparison and Scheffe methods were used to uncover variances place between the groups in pairs as shown in Table (6). 
Table 6. The post binary comparisons between the test score averages of the post/ delayed cognitive achievement test for the three research groups

\begin{tabular}{|c|c|c|c|c|c|}
\hline Test & Style (I) & Style (J) & Mean deferent $(I-J)$ & $\begin{array}{l}\text { Significance } \\
\text { Indicator }\end{array}$ & $\begin{array}{c}\text { Size effect } \\
\text { (Eta Square } \\
\eta 2 \text { ) } \\
\end{array}$ \\
\hline \multirow{3}{*}{$\begin{array}{l}\text { delayed Cognitive } \\
\text { achievement (after } \\
\text { 21Day/3week)=50 }\end{array}$} & \multirow[t]{2}{*}{ Short $<6 \mathrm{M}$} & $\begin{array}{l}\text { Medium } \\
(6-12 \mathrm{M})\end{array}$ & *17.095 & 0.719 & \\
\hline & & Long $>12 \mathrm{M}$ & *16.522 & 0.710 & 0.926 \\
\hline & $\begin{array}{l}\text { Medium } \\
(6-12 \mathrm{M})\end{array}$ & Long $>12 \mathrm{M}$ & -0.574 & & \\
\hline
\end{tabular}

The results in Table (6) reveal that the students who watched the short interactive videos, short $<6 \mathrm{M}$, achieved higher performance in the cognitive post-test than the performnace of students who watched mmedium 6-12M and long $>12 \mathrm{M}$ video. Statsitically significant variances were found at value 0.01 between performance of the groups in the cognitive post-test in favor of students who watched the short interactive video, short $<6 \mathrm{M}$, while no variance was found between students who watched medium $6-12 \mathrm{M}$ and students who watched long $>12 \mathrm{M}$ in their performance in the cognitive post-test, where there are no statistically significant variances between them.

Besides, the effect size was calculated using the equation of Eta ( $\eta 2)$. The effect size between the three experimental groups reached 0.926 in performance of cognitive post-test. This result indicates that there is a big effect size of the independent variable in the variance between the groups relating to its effect on the cognitive post-achievement, and the strong effect of the experimental treatment of short video, short $<6 \mathrm{M}$, in retention of learning compared to the performance of students who watched medium and long videos.

\section{Answering the Third Question}

What is the effect of difference in the interactive video length (Short< 6 minutes, Medium 6-12 minutes, and Long > 12 minutes) on learners' cognitive load?

One-way Analysis of Variance (ANOVA) was calculated to know the effect of difference in video length (short $<6 \mathrm{M}$, medium $6-12 \mathrm{M}$, and long $>12 \mathrm{M}$ ) on cognitive load with its three types (intrinsic, extraneous, and germane) and the overall cognitive load. The results obtained are presented in Table (7) Arithmetical averages and standard deviations for IDV length in performance on the three types of cognitive load scale, and Table (8) Arithmetical averages and standard deviations for IDV length in performance on the cognitive load scale.

Tabel 7. Arithmetical averages and standard deviations for IDV length (Short $<6 \mathrm{M}$, Medium 6-12 M, Long $>12 \mathrm{M}$ ) in performance on the cognitive load scale

\begin{tabular}{cccccccc}
\hline \multirow{2}{*}{$\begin{array}{c}\text { IDV length } \\
\text { Scale }\end{array}$} & \multicolumn{2}{c}{ Short $<6 \mathrm{M}$} & \multicolumn{2}{c}{$\begin{array}{c}\text { Medium } \\
(6-12 \mathrm{M})\end{array}$} & \multicolumn{2}{c}{ Long $>12 \mathrm{M}$} \\
\cline { 2 - 8 } & Mean & SD & Mean & SD & Mean & SD \\
\hline Intrinsic Load =40 degree & 16.41 & 3.83 & 28.75 & 3.89 & 28.75 & 3.89 \\
Extrades Load=40 degree & 13.77 & 3.70 & 29.20 & 3.47 & 30.00 & 3.36 \\
Germane Load =50 degree & 19.09 & 4.28 & 34.25 & 5.44 & 33.24 & 5.84 \\
All Cognitive Load =140 degree & 52.36 & 11.77 & 98.55 & 6.68 & 97.62 & 6.13 \\
\hline
\end{tabular}


Figure (2) explains the results presented in Table (7):

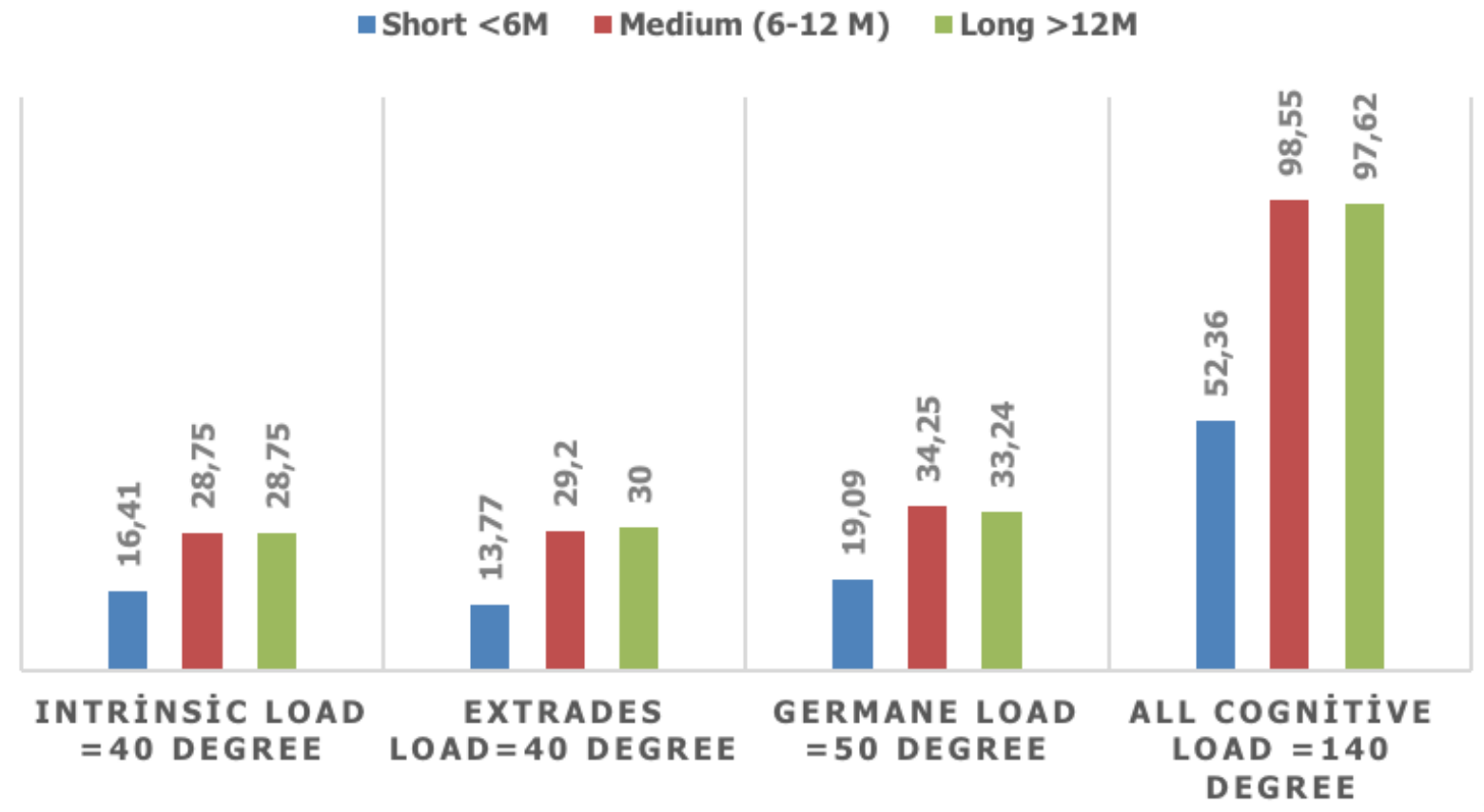

Figure 2. Arithmetical averages and standard deviations for IDV length (Short $<6 \mathrm{M}$, Medium 6-12 M, Long $>12 \mathrm{M}$ ) in performance on the cognitive load scale

Table 8. ANOVA, Arithmetical averages and standard deviations for IDV length (Short $<6 \mathrm{M}$, Medium 6-12 M, Long >12M) In performance on the cognitive load scale

\begin{tabular}{|c|c|c|c|c|c|c|}
\hline Scale & Variable source & $\begin{array}{l}\text { Sum of } \\
\text { squares }\end{array}$ & $\mathrm{df}$ & $\begin{array}{r}\text { Means } \\
\text { Squares }\end{array}$ & "F"value & $\begin{array}{l}\text { Significance } \\
\text { Indicator }\end{array}$ \\
\hline \multirow{3}{*}{$\begin{array}{l}\text { Intrinsic Load }=40 \\
\text { degree }\end{array}$} & Between Groups & 1979.63 & 2 & 989.81 & \multirow{3}{*}{58.32} & \multirow{3}{*}{0.000} \\
\hline & Within Groups & 1018.31 & 60 & 16.97 & & \\
\hline & Total & 2997.94 & 62 & & & \\
\hline \multirow{3}{*}{$\begin{array}{l}\text { Extrades Load=40 } \\
\text { degree }\end{array}$} & Between Groups & 3597.54 & 2 & 1798.77 & \multirow{3}{*}{145.2} & \multirow{3}{*}{0.000} \\
\hline & Within Groups & 743.06 & 60 & 12.38 & & \\
\hline & Total & 4340.60 & 62 & & & \\
\hline \multirow{3}{*}{$\begin{array}{c}\text { Germane Load }=50 \\
\text { degree }\end{array}$} & Between Groups & 3079.48 & 2 & 1539.74 & \multirow{3}{*}{56.77} & \multirow{3}{*}{0.000} \\
\hline & Within Groups & 1627.38 & 60 & 27.12 & & \\
\hline & Total & 4706.86 & 62 & & & \\
\hline \multirow{3}{*}{$\begin{array}{l}\text { All Cognitive Load } \\
\quad=140 \text { degree }\end{array}$} & Between Groups & 29923.22 & 2 & 14961.6 & & \multirow{3}{*}{0.000} \\
\hline & Within Groups & 4508.99 & 60 & 75.15 & 199.1 & \\
\hline & Total & 34432.22 & 62 & & & \\
\hline
\end{tabular}

Results in Table (8) indicate that there are statistically significant variances at the function value 0.01 between grades averages of students on the scale of the cognitive load types (intrinsic, extraneous, and germane), and the overall cognitive load. And this means that there is an effect of difference in video length $(\operatorname{short}<6 \mathrm{M}$, medium 6-12M, and long $>12 \mathrm{M}$ ) in the post-performance on the scale of cognitive load types (intrinsic, extraneous, and germane), and the overall cognitive load, which means that the third hypothesis validity is confirmed. To determine the place of theses variances, Post Hoc comparison and Scheffe methods were used to uncover the place of variances between the groups in pairs as shown in Table (9). 
Table 9. The post binary comparisons between the cognitive load scale for the three research groups

\begin{tabular}{|c|c|c|c|c|c|}
\hline Scale & Style (I) & Style (j) & $\begin{array}{c}\text { Mean deferent } \\
(I-J)\end{array}$ & $\begin{array}{l}\text { Significance } \\
\text { Indicator }\end{array}$ & $\begin{array}{c}\text { Size effect } \\
\text { (Eta Square } \eta 2)\end{array}$ \\
\hline \multirow{3}{*}{$\begin{array}{l}\text { Intrinsic Load } \\
=40 \text { degree }\end{array}$} & \multirow{2}{*}{ Short $<6 \mathrm{M}$} & $\begin{array}{l}\text { Medium } \\
(6-12 \mathrm{M})\end{array}$ & $-12.34^{*}$ & 0.000 & \\
\hline & & Long $>12 \mathrm{M}$ & $-11.12^{*}$ & 0.000 & 0.660 \\
\hline & $\begin{array}{l}\text { Medium } \\
(6-12 \mathrm{M})\end{array}$ & Long $>12 \mathrm{M}$ & 1.23 & 0.637 & \\
\hline \multirow{3}{*}{$\begin{array}{l}\text { Extrades } \\
\text { Load }=40 \\
\text { degree }\end{array}$} & \multirow[t]{2}{*}{ Short $<6 \mathrm{M}$} & $\begin{array}{l}\text { Medium } \\
(6-12 M)\end{array}$ & $-15.43^{*}$ & 0.000 & \\
\hline & & Long $>12 \mathrm{M}$ & $-16.23^{*}$ & 0.000 & 0.829 \\
\hline & $\begin{array}{l}\text { Medium } \\
(6-12 \mathrm{M})\end{array}$ & Long $>12 \mathrm{M}$ & -0.80 & 0.768 & \\
\hline \multirow{3}{*}{$\begin{array}{c}\text { Germane } \\
\text { Load }=50 \\
\text { degree }\end{array}$} & \multirow[t]{2}{*}{ Short $<6 \mathrm{M}$} & $\begin{array}{l}\text { Medium } \\
(6-12 M)\end{array}$ & $-15.16^{*}$ & 0.000 & \\
\hline & & Long $>12 \mathrm{M}$ & $-14.15^{*}$ & 0.000 & 0.654 \\
\hline & $\begin{array}{l}\text { Medium } \\
(6-12 \mathrm{M})\end{array}$ & Long $>12 \mathrm{M}$ & 1.01 & 0.825 & \\
\hline \multirow{3}{*}{$\begin{array}{l}\text { All Cognitive } \\
\text { Load }=140 \\
\text { degree }\end{array}$} & \multirow[t]{2}{*}{ Short $<6 \mathrm{M}$} & $\begin{array}{l}\text { Medium } \\
(6-12 M)\end{array}$ & $46.186^{*}$ & 0.000 & \\
\hline & & Long $>12 \mathrm{M}$ & $-45.26^{*}$ & 0.000 & 0.869 \\
\hline & $\begin{array}{l}\text { Medium } \\
(6-12 \mathrm{M})\end{array}$ & Long $>12 \mathrm{M}$ & -0.93 & 0.943 & \\
\hline
\end{tabular}

Results in Table (9) reveal that the performance of students who watched the interactive video with short length, short $<6 \mathrm{M}$ achieved higher results in reduicing the cognitive load compared to srudents who watched medium 6-12M and long $>12 \mathrm{M}$ interactive video length. Statistically significant variances were found at the value 0.01 between the performance of the three groups on cognitive load scale in favor of students who watched the short interactive video short $<6 \mathrm{M}$. Also, there were statsitically significant variances between students who watched the interactive video with medium 6-12M length and students who watched the long interactive video, long $<12 \mathrm{M}$, in their performance on the cognitive load scale, which showed that performance of students with medium length was better than students of long videos.

Besides, the effect size was calculated using the equation of Eta ( $\eta 2)$. The effect size between the three experimental groups reached $(0.660,0.829,0.654,0.869)$ for the intrinsic, extraneous, germane, and the overall cognitive load respectively, which are high effect size values on cognitive load. This result indicates that there is a big effect size of the independent variable in the variance between the groups relating to reducing the cognitive load; and this reflects that there is a strong effect of the experimental treatment of short video length, short $<6 \mathrm{M}$, in reducing the cognitive load compared to the performance of students who watched medium and long videos.

\section{DISCUSSION}

\section{Explaining the Results Related to the Effect of Difference in the Interactive Video Length (Short $<6 \mathrm{M}$, Medium 6-12M, and Long $>12 \mathrm{M}$ ) on Students' Performance in the Test of Immediate Cognitive Achievement, and Their Performance in the Post-Test (Delayed Testing) Relating to Retention of Learning.}

The results revealed that students who practiced learning trough videos with short length, short $<6 \mathrm{M}$ achieved higher results in the immediate cognitive achievement, and in the post-test compared to students who watched medium $6-12 \mathrm{M}$ and long $>12 \mathrm{M}$. On the other hand, the results showed no difference between the students who learnt through medium 6-12M compared to the students who learnt through long $>12 \mathrm{M}$ videos in their performance in the immediate cognitive achievement test and the post-test. This means that students who learnt trough short videos maintain knowledge, concepts, and skills longer than medium and long video groups, and thus retention of learning is longer. 
These findings come in consistency with the results of various previous studies. The findings of the study (Hung \& Chen, 2018) showed that students who practiced learning through the short interactive video achieved better performance at the level of understanding and retention of information in the memory. Also, another study (Razis, Radzuan, \& Manan, 2018) revealed that learners who used short interactive videos to complete skills showed big improvement in retention of information besides supporting learning compared to the other group who did not use the video in learning. This comes also in compliance with the findings of (Risko et al., 2012) which showed that mental stray cases in students who learnt through long videos were high, while the retention of information was low after watching the long video. The study of (Guo, et al., 2014) also considered making video length more than 6 minutes, that is 6-9 is a mere waste of learner's effort. And this result can be explained as follows:

- Using interactive elements in the interactive video and using short and brief videos could have helped in reducing mental stray, and increased students' engagement and their deep interaction with the training content included in the video. And this was not available with medium and long videos which could have been watched passively by students because the length of the video is medium or long, which may result in watching without interaction of students either by answering questions, or other forms of interaction.

- Also, diversity in practice and re-watching of short videos have an important effect in retention of learning, where the short interactive video helped in continuous students' performance and the continuity of connection between stimuli and responses for a long time which leads in turn to achieving learning and its retention.

- Besides, prevention of interference and conflict between information through short videos which focused on specific skill at a time or on a specific rule of digital photography has an important role in eliminating confusion that may be caused by interference or conflict. This is because students are likely to forget information when there is interference between ideas. Thus, avoiding interference between a set of ideas and another set reduces forgetting, and contributes to remembering and retention of learning; and this was not available with medium and long videos which show a number of varied topics and skills leading to interference and forgetting and thus to the absence of retention for long time.

This result goes in line with the Cognitive Theory of Multimedia Learning which reveals that students are more cognitively active in building learning when they integrate in a meaningful learning process. And this process occurs when learners choose the new information from old stimuli and make effort to complement and integrate them with the previous knowledge they own. And this is what the short interactive video provided to assist in more engagement of learners and their interaction with the learning content. Also, the results are supported by the Theory of Cognitive Processing of Information which assumes that attention of learners is limited, and thus this attention should be directed in a selective manner. Thereby, by providing more rich and engaging media, learners who prefer the interactive video style can satisfy their personal learning needs (Zhang, et. al., 2006). In light of tis theory, we conclude that the short learning video which provides varied interactive learning activities will be more effective in achievement and learning retention by learners.

\section{Explaining the Results Related to the Effect of Difference in the Interactive Video Length (Short $<6 \mathrm{M}$, Medium 6-12M, and Long $>12 \mathrm{M}$ ) on the Cognitive Load of Learners}

The results revealed that the performance of students who watched short $<6 \mathrm{M}$ videos was higher in reducing the cognitive load than the performance of students who watched medium 6-12M and long $>12 \mathrm{M}$ learning videos. Also, there were statistically significant variances between students who learnt through the interactive video with medium 6-12M length and students who learnt through the long interactive video, long $>12 \mathrm{M}$, in their performance on the cognitive scale in favor of students who learnt through medium videos.

This result is consistent with the findings of the previous studies which revealed that using short interactive videos does not exhaust students with any extra cognitive load (Hung, \& Chen, 2018). This result is also supported by the Cognitive Load Theory which sees that reducing the cognitive load on the working memory facilitates decoding and stocking information which can be achieved by reducing the cognitive load in the visual channel. And this result can be explained as follows: 
- Short videos focused on the required information only to make learning happens and remove information which can be exhausting for the working memory, and which students do not need to achieve learning. Besides, unneeded information may cause distraction in learner's focus. And thus, removing them contributed to reducing the extraneous cognitive load resulting from mal-design process of the video. On the other hand, long videos may present too much information which are not needed in the learning objective or not assimilated by the working memory of the learners as their mental capacity is limited. This was proved by the study of Ibrahim et al., (2012) as the pruning process can improve information transmission from the video and long retention in the memory of learners (Ibrahim, et. al., 2012).

- The educational design of short interactive videos took into consideration using chunking or segmenting strategy, which enabled students to interact with short videos, and helped them control new information flow and interact with the core information. This contributed to reducing the intrinsic cognitive load and increased the germane load through focusing on information building process. Segmenting of videos reduces the cognitive load which results from passage of information because it allows having the needed time to process the presented information without having to deal with a new set of information at the same time (Biard, Cojean, \& Jamet, 2018; Rudolph, 2017).

- Also, using 'auto-pause' strategy or 'interactive questions' in the interactive video has an effect on increasing learners' interaction with content, which reduced the intrinsic cognitive load for students of the experimental group who used short videos. This is affirmed by the findings of the previous studies about the interaction of students with the video and their engagement in the learning process, and that using short videos reduces the cognitive load for learners (Guo, et al., 2014; Ibrahim et al., 2012). On the opposite, the students during learning through medium and long videos might have been passive viewers who did not watch the video to the end because of being long unlike the short video, which has led the difference in students' performance in favor of students of the experimental group who learnt through short videos compared to groups of medium and long videos, relating to the performance on the scale of the cognitive load types (intrinsic, extraneous, germane) and the overall cognitive load.

\section{CONCLUSION}

The results revealed that the performance of students who learnt through short $<6 \mathrm{M}$ videos achieved better results in the immediate cognitive achievement, and post-cognitive achievement which is retention of learning effects in the long term. They have also achieved better results in reducing the cognitive load compared to the results of students who learnt through medium and long videos. On the other hand, no difference is noticed between the performance in the immediate cognitive achievement test and the posttest for students who watched the medium interactive videos, medium 6-12M, compared to students who watched the long interactive videos, long $>12 \mathrm{M}$. Thus there are no statistically significant variances between them. But, there were statsitically significant variances between students of the same two groups, medium $6-12 \mathrm{M}$ length videos group and long $<12 \mathrm{M}$ videos group, in their performance on the cognitive load scale, which showed that the performance of students who learnt through videos with medium length was better than the performance of students of long videos group. 


\title{
RECOMMENDATIONS
}

In light of the findings of this research, the researcher presents some recommendations to benefit from while designing the learning environments which are based on the interactive video as follows:

1. It is preferable to use short videos that can reduce the cognitive load on learners, and contribute to retention of learning by learners, besides contributing to creating an appealing learning environment, and increasing students' engagement, as well as providing learning opportunities and retention of learning for a long time.

2. It is better to avoid mal-design of digital video-based learning resources because it can be an extra cognitive burden and extra effort for learners.

3. The adoption of services of learning and training based on the interactive video by stakeholders especially universities, schools and companies, besides the development of the required learning content in the light of designs standards of short interactive videos.

4. Training the members of the teaching body in universities and schools on designing interactive videobased learning environments to design short interactive videos related to the learning content, as well as training them on how to use these videos in the light of design standards, besides providing them with knowledge of how to create and use them.

5. Taking into consideration personal characteristics that urge the adoption of learning and training based on the interactive video, because forming a positive view by these people towards interactive video-based learning, and knowing that the required mental effort will be reduced will lead to positive results, and thus to the actual adoption of this technology in teaching and training.

Besides, the researcher suggests conducting more research studies in the field of training and learning through interactive video-based learning environments to study other variables which this study did not address, including:

1. Comparing the effect of different styles of interactive questions (exploratory questions vs inductive questions) in the interactive video on some of learning outcomes

2. Investigating interactive activities within the interactive video (interactive questions vs hotspots) and their effect on some learning outcomes

3. Studying the relationship between the variables of user interaction with the interactive video (individual vs synchronous with others) on some learning outcomes.

\section{BIODATA and CONTACT ADDRESSES of AUTHOR}

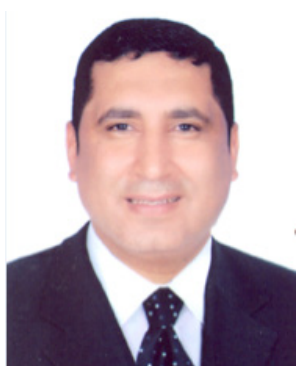

Dr. Mohammed Kamal AFIFY is a Professor of Educational Technology College of Education, Imam Abdulrahman Bin Faisal University, Saudi Arabia. Dr. Afify gained his Ph.D. in Educational Technology at May, 2004, from Arish University, Egypt. He has authored a numerous article in the field and published extensively in different areas. His research interests vary from applying educational technology in higher education to quality standards and implementations in eLearning environments.

\author{
Mohammed Kamal AFIFY \\ Department of Educational Technology, College of Education \\ Imam Abdulrahman Bin Faisal University \\ Address: P. O. Box 1982, Dammam, 31441, Saudi Arabia \\ Phone: 00966569877695 \\ Email: mafify@iau.edu.sa
}




\section{REFERENCES}

Alpert, F., \& Hodkinson, C. S. (2019). Video use in lecture classes: current practices, student perceptions and preferences. Education and Training, 61(1), 31-45.

Ariffin, S. N. M., \& Ismail, M. (2019). Design of the Icon-Based Interactive Video for English Vocabulary Learning. In Proceedings of the Regional Conference on Science, Technology and Social Sciences (RCSTSS 2016) (pp. 203-212). Springer, Singapore.

Baldwin, S., \& Ching, Y. H. (2017). Interactive Storytelling: Opportunities for Online Course Design. TechTrends, 61(2), 179-186.

Betrancourt, M., \& Benetos, K. (2018). Why and when does instructional video facilitate learning? A commentary to the special issue "developments and trends in learning with instructional video". Computers in Human Behavior, 89, 471-475.

Biard, N., Cojean, S., \& Jamet, E. (2018). Effects of segmentation and pacing on procedural learning by video. Computers in Human Behavior, 89, 411-417

Blackstock, D., Edel-Malizia, S., Bittner, K., \& Smithwick, E. (2017, June). Investigating interactive video assessment tools for online and blended learning. In International Conference on e-Learning (pp. 31-39). Academic Conferences International Limited.

Brame, C. J. (2016). Effective educational videos: Principles and guidelines for maximizing student learning from video content. CBE-Life Sciences Education, 15(4), es6.

Branch, R. M. (2009). Instructional design: The ADDIE approach (Vol. 722). Springer Science \& Bus

Dash, S., Kamath, U., Rao, G., Prakash, J., \& Mishra, S. (2016). Audio-visual aid in teaching "fatty liver". Biochemistry and Molecular Biology Education, 44(3), 241-245.

Delen, E., Liew, J., \& Willson, V. (2014). Effects of interactivity and instructional scaffolding on learning: Self-regulation in online video-based environments. Computers \& Education, 78, 312-320.

Fern, A., Givan, R., \& Siskind, J. M. (2011). Specific-to-general learning for temporal events with application to learning event definitions from video. Journal of Artificial Intelligence Research, 17, 379-449.

Giannakos, M. N., Jaccheri, L., \& Krogstie, J. (2016). Exploring the relationship between video lecture usage patterns and students' attitudes. British Journal of Educational Technology, 47(6), 1259-1275.

Green, M. (2016). How to effectively use interactive videos in eLearning? Retrieved 22nd Jun, 2016 from https://www.brightcarbon.com/blog/effectively-use-interactive-videos-in-elearning/

Guo, P. J., Kim, J., \& Rubin, R. (2014, March). How video production affects student engagement: an empirical study of MOOC videos. In Proceedings of the first ACM conference on Learning@ scale conference (pp. 41-50). ACM.

Hung, I. C., \& Chen, N. S. (2018). Embodied interactive video lectures for improving learning comprehension and retention. Computers \& Education, 117, 116-131.

Ibrahim, M., Antonenko, P. D., Greenwood, C. M., \& Wheeler, D. (2012). Effects of segmenting, signalling, and weeding on learning from educational video. Learning, Media and Technology, 37(3), 220-235.

Jill, M. D., Wang, D., \& Mattia, A. (2019). Are instructor generated YouTube videos effective in accounting classes? A study of student performance, engagement, motivation, and perception. Journal of Accounting Education.

Josephsen, J. (2018). Cognitive Load Measurement, Worked-Out Modeling, and Simulation. Clinical Simulation in Nursing, 23, 10-15.

Kruger, J. L., \& Doherty, S. (2016). Measuring cognitive load in the presence of educational video: Towards a multimodal methodology. Australasian Journal of Educational Technology, 32(6).

Leppink, J., Paas, F., Van der Vleuten, C. P., Van Gog, T., \& Van Merrienboer, J. J. (2013). Development of an instrument for measuring different types of cognitive load. Behavior research methods, 45(4), 1058-1072. 
Leppink, J., Paas, F., Van Gog, T., van Der Vleuten, C. P., \& Van Merrienboer, J. J. (2014). Effects of pairs of problems and examples on task performance and different types of cognitive load. Learning and Instruction, 30, 32-42.

Mayer, R. (2014). Cognitive theory of multimedia learning. The cambridge handbook of multimedia learning (2nd ed.), Cambridge University Press (2014), p. 72

Mayer, R. E., \& Moreno, R. (2003). Nine ways to reduce cognitive load in multimedia learning. Educational psychologist, 38(1), 43-52.

Mayer, R. , Pilegard, C. (2014). Principles for managing essential processing in multimedia Learning: Segmenting, pre-training, and modality principles. The Cambridge Handbook of Multimedia Learning (2nd ed.), Cambridge University Press, Cambridge (2014), pp. 316-344.

Meixner, B. (2017). Hypervideos and interactive multimedia presentations. ACM Computing Surveys (CSUR), 50(1), 9.

Merkt, M., \& Schwan, S. (2014). Training the use of interactive videos: effects on mastering different tasks. Instructional Science, 42(3), 421-441.

Paas, F., Renkl, A., \& Sweller, J. (2003a). Cognitive load theory and instructional design: Recent developments. Educational psychologist, 38(1), 1-4.

Paas, F., Tuovinen, J. E., Tabbers, H., \& Van Gerven, P. W. (2003b). Cognitive load measurement as a means to advance cognitive load theory. Educational psychologist, 38(1), 63-71.

Palaigeorgiou, G., \& Papadopoulou, A. (2018). Promoting self-paced learning in the elementary classroom with interactive video, an online course platform and tablets. Education and Information Technologies, 1-19.

Palaigeorgiou, G., Papadopoulou, A., \& Kazanidis, I. (2018, June). Interactive Video for Learning: A Review of Interaction Types, Commercial Platforms, and Design Guidelines. In International Conference on Technology and Innovation in Learning, Teaching and Education (pp. 503-518). Springer, Cham.

Pandey, A. (2018). How Can You Use Interactive Videos Effectively In eLearning? Retrieved March 27th, 2018 from https:/www.eidesign.net/can-use-interactive-videos-effectively-elearning/

Petan, A. S., Petan, L., \& Vasiu, R. (2014). Interactive video in knowledge management: Implications for organizational leadership. Procedia-Social and Behavioral Sciences, 124, 478-485.

Plass, J. L., Moreno, R., \& Brunken, R. (Eds.). (2010). Cognitive load theory. Cambridge University Press.

Razis, S. N. I. M., Radzuan, L. E. M., \& Manan, J. (2018). Improving Teaching and Learning Module Through Implementation of Mnemonic Method and Interactive Video for Subject of History Studies. In Proceedings of the Art and Design International Conference (AnDIC 2016) (pp. 431435). Springer.

Risko, E. F., Anderson, N., Sarwal, A., Engelhardt, M., \& Kingstone, A. (2012). Everyday attention: Variation in mind wandering and memory in a lecture. Applied Cognitive Psychology, 26(2), 234242.

Rismark, M., \& Sølvberg, A. M. (2019). Video as a Learner Scaffolding Tool. International Journal of Learning, Teaching and Educational Research, 18(1).

Rudolph, M. (2017). Cognitive theory of multimedia learning. Journal of Online Higher Education, 1(2), $1-10$.

Sauli, F., Cattaneo, A., \& van der Meij, H. (2018). Hypervideo for educational purposes: a literature review on a multifaceted technological tool. Technology, pedagogy and education, 27(1), 115-134.

Shahrokni, S. E. (2018). Using interactive video in learning education. Teaching English with Technology, 18(1), 105-115.

Shelton, C. C., Warren, A. E., \& Archambault, L. M. (2016). Exploring the use of interactive digital storytelling video: Promoting student engagement and learning in a university hybrid course. TechTrends, 60(5), 465-474. 
Slemmons, K., Anyanwu, K., Hames, J., Grabski, D., Mlsna, J., Simkins, E., \& Cook, P. (2018). The impact of video length on learning in a middle-level flipped science setting: implications for diversity inclusion. Journal of Science Education and Technology, 27(5), 469-479.

Song, H. S., Pusic, M., Nick, M. W., Sarpel, U., Plass, J. L., \& Kalet, A. L. (2014). The cognitive impact of interactive design features for learning complex materials in medical education. Computers \& education, 71, 198-205.

Staff, E. (2014). EDpuzzle review: Easy-to-use tool lets teachers quickly turn online video into lessons. Retrieved April, 1, 2016.

Sweller, J. (1994). Cognitive load theory, learning difficulty, and instructional design. Learning and instruction, 4(4), 295-312.

Sweller, J. (2010). Element interactivity and intrinsic, extraneous, and germane cognitive load. Educational psychology review, 22(2), 123-138.

Sweller, J., Ayres, P., \& Kalyuga, S. (2011). Measuring cognitive load. In Cognitive load theory (pp. 71-85). Springer, New York, NY.

Wachtler, J., Hubmann, M., Zohrer, H., \& Ebner, M. (2016). An analysis of the use and effect of questions in interactive learning-videos. Smart Learning Environments, 3(1), 13.

Wachtler, J., Scherz, M. \& Ebner, M. (2018). Increasing learning efficiency and quality of students' homework by attendance monitoring and polls at interactive learning videos. In Proceedings of EdMedia: World Conference on Educational Media and Technology (pp. 1337-1347). Amsterdam, Netherlands: Association for the Advancement of Computing in Education (AACE).

Wang, J., \& Antonenko, P. D. (2017). Instructor presence in instructional video: Effects on visual attention, recall, and perceived learning. Computers in human behavior, 71, 79-89. 